\title{
PENDIDIKAN IDEAL PERSPEKTIF TAGORE DAN KI HAJAR DEWANTARA DALAM PEMBENTUKAN KARAKTER PESERTA DIDIK
}

\author{
Marzuki dan Siti Khanifah \\ Prodi PPKn Program Pascasarjana Universitas Negeri Yogyakarta \\ marzuki@uny.ac.id
}

\begin{abstract}
The research aims to study the thought of Rabindranath Tagore and Ki Hajar Dewantara with the ideal education related in formation of students character. This research is a literature review using content analysis approach. Sources of data in the form of primary data and secondary data on thought of two leaders in education. Data were analyzed qualitatively with the inductive approach. The results showed that 1) Rabindranath Tagore saw education based on freedom and love. Learning approach undertaken by Rabindranath Tagore in the education system is experiential learning; 2) Ki Hajar Dewantara developed a Among system in education which is an effort to advance the development of morality (inner strength), mind (intellect), and physical students; and 3) there is a link between thought of Rabindranath Tagore and thought of Ki Hajar Dewantara on looking at the education and development of ideal education system.
\end{abstract}

Keywords: Education, Rabindranath Tagore, Ki Hajar Dewantara, character formation, and students.

\section{PENDAHULUAN}

Perkembangan dunia yang kompetitif saat ini memaksa peserta didik untuk belajar lebih keras. Sekolah sebagai produsen pendidikan bersaing untuk menghasilkan peserta didik dengan kualitas yang mampu bertahan di kancah global. Anis Matta (Kurniawan \& Hindarsih, 2013, p. 5) memandang "jam-jam pembelajaran di sekolah seperti 'pengisian' ilmu pada peserta didik yang merupakan 'robot cerdas"'.

Guru dan mentor menciptakan kepanikan di pikiran peserta didik dari awal pembelajaran, bahwa ilmu pengetahuan merupakan kebutuhan dasar yang harus dimiliki oleh setiap orang agar bisa bertahan hidup. Kondisi tersebut, bagi Guha (2013, p. 36) membuat pendidikan jauh dari cintakasih. Pendidikan di sekolah yang harusnya transfer of value, pada akhirnya hanya sebatas transfer of knowledge (Putri, 2012, p. 3). Pada tahap ini, pengkajian terhadap pendidikan yang ideal menjadi penting untuk dilakukan. Pemikiran Rabindranath Tagore dan Ki Hajar Dewantara menjadi layak untuk dikaji dewasa ini. Rabindranath Tagore merupakan tokoh pendidikan dari India, sedangkan Ki Hajar Dewantara merupakan "Bapak Pendidikan Indonesia". Keduanya memiliki perhatian khusus terkait pendidikan, terutama pendidikan ideal dengan "transfer of value", atau dalam konteks sekarang disebut pendidikan karakter.

Literasi terkait pemikiran $\mathrm{Ki}$ Hajar Dewantara tentang pendidikan karakter telah banyak disajikan. Akan tetapi, belum banyak yang menyandingkannya dengan pemikiran Rabindranath Tagore. Pada penelitian ini penulis mengkaji secara kritis terkait pemikiran dua tokoh besar tersebut dalam kaitannya dengan pendidikan karakter. Fokus kajian dalam penelitian ini adalah pandangan atau pemikiran Rabindranath Tagore dan pemikiran Ki Hajar Dewantara tentang 
pendidikan yang ideal terkait pembentukan karakter peserta didik, serta keterkaitan antara pemikiran Rabindranath Tagore dan pemikiran Ki Hajar Dewantara dalam memandang pendidikan yang ideal dalam pembentukan karakter peserta didik.

\section{METODE}

Penelitian ini merupakan kajian studi pustaka dengan menggunakan pendekatan content analysis (analisis isi). Sumber data dalam penelitian ini berupa sumber primer dan sumber sekunder. Sumber primer meliputi kumpulan karya $\mathrm{Ki}$ Hajar Dewantara, khususnya dalam buku, " $\mathrm{Ki}$ Hajar Dewantara Bagian Pertama; Pendidikan" dan tulisan Rabindranath Tagore, khususnya "Gita Anjali". Sumber sekunder berupa tulisan atau karya orang lain tentang $\mathrm{Ki}$ Hajar Dewantara atau Rabindranath Tagore.

Pengumpulan data dilakukan dengan teknik library research (penelitian pustaka). Data yang telah terkumpul kemudian dianalisis secara kualitatif dengan pendekatan induktif dengan mengacu pada permasalahan yang ada. Unit analisis meliputi data dari kedua pemikiran tokoh yang diteliti terkait dengan pendidikan ideal dalam pembentukan karakter peserta didik.

\section{HASIL DAN PEMBAHASAN}

\section{Pendidikan Ideal dalam Pembentukan Karakter Perspektif Tagore}

Bagi Tagore, peserta didik bukanlah penerima pasif pengetahuan tetapi penemu fakta dan prinsip-prinsip (Desai, 2010, p. 631). Oleh karena itu, pendidikan harus dikelola pada kondisi yang bebas dan menyenangkan. Hal tersebut menunjukkan orisinalitas pandangan Tagore terkait pendidikan yaitu bukan pada tujuan, tetapi pada kegiatan (Desai, 2010, p. 629). Pendidikan menurut Tagore tidak hanya tentang tujuan akhir untuk mencari pekerjaan, akan tetapi melakukan pembangunan (Guha, 2013, p. 37). Ia menegaskan, pendidikan haruslah mencerahkan, bukan sekadar menghasilkan pekerja untuk pabrik-pabrik kantor (Samuel, 2010, p. 650).

Rabindranath Tagore menganggap "kebebasan" peserta didik merupakan hal yang penting dalam kegiatan pembelajaran (Guha, 2013, p. 39). Kebebasan pikiran peserta didik akan menimbulkan kreativitas (Desai, 2010, p. 630). Tagore tidak menyukai pendidikan formal karena menurutnya sekolah-sekolah menyerupai pabrik atau penjara yang tidak bernyawa, tidak berwarna, muram, dan merupakan lembaga yang menakutkan. Sekolah membentuk peserta didik seperti burung beo dalam sangkar emas, terisolasi dari perubahan alami dalam masyarakat (Pridmore, 2009; Samuel, 2010).

Pada kesempatan yang lain, Tagore menjelaskan bahwa pengetahuan spiritual sama pentingnya dengan ilmiah. Keduanya penting untuk mengembangkan kepercayaan dalam belajar dan hidup. Hal ini karena mengembangkan kepercayaan diri penting untuk kepribadian seorang individu yang memungkinkannya untuk menerima kekuatan serta kelemahan. Kepercayaan diri peserta didik merupakan keunggulan bagi penerimaan kelemahan dan kesalahan seseorang. Hal tersebut memainkan peran penting dalam konsepsi diri untuk memperdalam penghargaan bagi diri sendiri (Guha, 2013). Karakter peserta didik itulah yang menjadi tujuan dari pendidikan.

Fokus pengembangan pendidikan Rabindranath Tagore yaitu pendidikan yang menyenangkan bagi peserta didik, agar karakter peserta didik dapat terbentuk. Tagore 
telah menemukan bahwa sistem pendidikan yang menghadirkan tekanan, sebagaimana beliau sendiri mengalami berdampak pada ketakutan ketika belajar. Oleh karena itu, Tagore mendirikan lembaga pendidikan Visva Bharati di Shantiniketan dengan suasana pembelajaran yang menghadirkan kebebasan. Tagore membudayakan disiplin internal dalam suasana suka cita dan motivasi tanpa adanya rasa takut (Guha, 2013, p. 37).

Budaya tersebut menjadikan peserta didik lebih menikmati proses belajar tanpa rasa takut dalam lembaga pendidikan. Disiplin diperlukan dalam proses pembelajaran, akan tetapi disiplin yang berlebihan akan menimbulkan peserta didik takut dan tidak adanya keinginan untuk aktif dalam pembelajaran, bahkan dapat berdampak pada peserta didik tidak ingin belajar (Guha, 2013, p. 37). Oleh karena itu, Tagore lebih tertarik membangun budaya dibandingkan mengajarkan trik-trik agar peserta didik lulus ujian (Ghosh, 2015, p. 406).

Pendekatan pembelajaran yang dilakukan oleh Rabindranath Tagore dalam sistem pendidikan yaitu experiential learning (Guha, 2013, p. 37). Tagore menganggap bahwa pendidikan adalah proses sosial yang terus menerus dan harus dikaitkan dengan kehidupan ekonomi dan sosial masyarakat, sehingga sekolah disebut sebagai miniatur masyarakat (Samuel, 2011, p. 1166). Pola tersebut terlihat dari model pendidikan Shantiniketan, yang di dalamnya Tagore memberikan pengalaman belajar di luar ruangan yang sangat menarik dan nyaman (Guha, 2013: 39).

Peningkatan kelangsungan hidup secara signifikan hanya mungkin jika kita bisa memahami esensi dari belajar dan berbagi penuh kasih dengan hidup. Perlu kiranya pendidikan yang dilakukan dapat mendorong pemberdayaan peserta didik dalam mengapresiasi pentingnya kepedulian dan berbagi dalam suatu masyarakat. Kepedulian merupakan aspek penting dalam membentuk karakter atau moral peserta didik. Oleh karena itu, perlu dibentuk suasana penuh dengan kebahagiaan dan sukacita (Guha, 2013, p. 40).

Pada kesempatan ini, guru memiliki peran layaknya tukang kebun yang membantu peserta didik tumbuh sendiri (Desai, 2010; Ghosh, 2015; Guha, 2013; Jha, 1999; Quayum, 2016; Samuel, 2010). Guru adalah panduan dan direktur yang mengarahkan perahu, tetapi energi yang mendorong itu harus datang dari orang-orang yang sedang belajar. Semakin guru menyadari pengalaman masa lalu peserta didik, harapan, keinginan, dan kepentingannya, maka guru lebih baik memahami kekuatan di tempat kerja yang perlu diarahkan dan dimanfaatkan untuk pembentukan kebiasaan reflektif peserta didik. Guru perlu menghubungkan tugasnya dengan aspirasi peserta didik untuk mencapai pikiran dan mengembangkan alat yang akan membantu guru menyadari dari latar belakang peserta didik, perkembangan emosinya, dan sebagainya (Guha, 2013, p. 41).

Penjelasan di atas menunjukkan bahwa Tagore menginginkan pendidikan yang "ideal" bagi pembentukan karakter peserta didik. Quayum (Quayum, 2016, p. 4) menyimpulkan tiga prinsip dasar dari visi pendidikan Tagore, yaitu kebebasan untuk peserta didik, penciptaan lingkungan yang memungkinkan peserta didik untuk mengembangkan kekerabatan yang sehat dengan alam, dan budidaya kreativitas peserta didik atau imajinasi. Sedangkan menurut Singh \& Rawat (2013, p. 202) inti dari konsep pendidikan Tagore yaitu lebih menekankan pada pengembangan harmonis lengkap pada kepribadian individu peserta 
didik. Tagore percaya bahwa pendidikan harus membantu seorang individu untuk mencapai kedewasaan, sehingga semua kekuatannya dapat dikembangkan untuk diri sendiri serta kesempurnaan masyarakat manusia tempat ia dilahirkan. Tagore percaya bahwa pendidikan bukan hanya sarana untuk pertumbuhan dan kepenuhan individu, tetapi juga berkaitan dengan lingkungan fisik dan sosial secara keseluruhan.

Pada pandangan Tagore, tujuan pendidikan yang lebih tinggi adalah sama dengan kehidupan seseorang, yaitu untuk mencapai pemenuhan dan kelengkapan. Tujuan yang lebih rendah yaitu menyediakan individu dengan sarana memuaskan mata pencaharian. Tagore juga membayangkan bahwa pengembangan terbatas manusia adalah hanya mungkin dalam lingkungan yang bebas dari segala bentuk perbudakan (Desai, 2010, p. 635). Selain itu, pendidikan, menurut Tagore, harus memfasilitasi pertumbuhan individu, pengembangan masyarakat, dan peningkatan masyarakat internasional (Samuel, 2010, p. 349). Tentu saja, filosofi pendidikan Tagore dan pada praktiknya tidak sempurna. Hal ini adalah salah satu mimpi manusia yang berpikir sebagai cara terbaik. Teori dan praktik mungkin tidak ditransplantasikan di sekolahsekolah saat ini. Namun, filsafat pendidikan tersebut, pedagogi, dan kurikulum dapat menginspirasi pendidik dari abad ke-21 (Samuel, 2010, p. 354).

Berdasarkan penjelasan di atas dapat disimpulkan bahwa pendidikan ideal bagi Rabindranath Tagore yaitu pendidikan yang humanis serta memberikan kebebasan dan cinta bagi peserta didik. Guru memiliki peran untuk merawat peserta didik, tanpa melakukan intervensi atau memaksanya. Dengan cara demikian, pembentukan karakter mandiri, disiplin, tanggung jawab bagi peserta didik dapat terbentuk.

\section{Pendidikan Ideal Perspektif Ki Hajar Dewantara dalam Pembentukan Karakter Peserta Didik}

Dewantara (Dewantara, 2011, p. 20) menjelaskan pemahaman terkait pendidikan yakni "menuntun segala kekuatan kodrat yang ada pada anak-anak, agar mereka sebagai manusia dan sebagai anggota masyarakat dapat mencapai keselamatan serta kebahagiaan yang setinggi-tingginya." Singkatnya, pendidikan bagi Ki Hajar Dewantara (Kumalasari, 2015) berarti upaya untuk memajukan perkembangan budi pekerti (kekuatan batin), pikiran (intelektual), dan jasmani peserta didik. Peserta didik hanya dapat berkembang ketika pendidikan dilakukan tanpa paksaan dan tanpa perintah.

Pandangan tersebut merupakan bentuk kritik Ki Hajar Dewantara pada pendidikan Barat yang menurutnya dasar dari pendidikan Barat yaitu perintah, hukuman, dan ketertiban. Dasar pendidikan tersebut menjadikan peserta didik akan rusak budi pekertinya (Dewantara, 2011, p. 13). Pendidikan sebagai "tuntunan" menunjukan bahwa di dalam pertumbuhan peserta didik dapat dipengaruhi oleh banyak hal dan pendidikan memiliki perannya di sana.

Bagi Ki Hajar Dewantara, peran pendidikan tersebut terkait dengan pembentukan budi pekerti. Jika peserta didik tidak baik "dasar jiwanya", tentu ia harus mendapatkan pendidikan agar bertambah baik budi pekertinya. Peserta didik yang tidak baik 'dasar jiwanya' dan tidak mendapat pendidikan akan mudah menjadi orang yang jahat atau buruk adabnya (Dewantara, 2011, p. 2011). "Dasar jiwa" yaitu keadaan jiwa yang asli menurut kodratnya sendiri, sebelum mendapat pengaruh dari luar. 
Teori "dasar jiwa" tersebut dapat dilihat dari tiga aliran. Pertama, teori tabula rasa (lapisan lilin yang masih dapat dicoret-coret oleh pendidik). Teori ini memandang bahwa peserta didik diumpamakan seperti sehelai kertas yang belum ditulis, sehingga pendidik boleh mengisi kertas yang kosong tersebut menurut kehendaknya. Artinya pendidik berkuasa seluasnya untuk membentuk watak atau budi pekerti seperti yang diinginkannya. Kedua, aliran negatif yang memandang peserta didik lahir sebagai sehelai kertas yang sudah ditulisi sepenuhnya hingga tidak memungkinkan pendidikan dari siapa pun dapat mengubah watak peserta didik. Pendidikan hanya dapat mengawasi agar tidak sampai ada pengaruh jahat yang mendekati peserta didik. Pendidikan menurut teori ini dianggap dapat menolak pengaruh dari luar dan mewujudkan budi pekerti yang tidak tampak ada dalam jiwa peserta didik (Dewantara, 2011, pp. 22-23). Ketiga, teori konvergensi, yaitu teori yang memandang peserta didik yang dilahirkan dapat diumpamakan sehelai kertas yang telah ditulisi penuh, akan tetapi tulisan tersebut masih suram. Menurut aliran ini, pendidikan berkewajiban dan berkuasa menebalkan segala tulisan yang suram dan mengisinya dengan kebaikan, agar tampak sebagai budi pekerti yang baik. Segala tulisan yang mengandung arti jahat agar jangan sampai menjadi tebal (Dewantara, 2011, p. 23).

Berdasarkan ketiga teori tersebut, Ki Hajar Dewantara lebih cenderung pada teori konvergensi. Pada penjelasannya, teori konvergensi membagi watak manusia menjadi dua. Bagian pertama dinamakan bagian intelligible yakni yang berhubungan dengan kecerdasan angan-angan atau pikiran yang dapat berubah karena pengaruh pendidikan atau keadaan. Bagian kedua merupakan bagian biologis (malu, takut, pemarah, dll) dan tidak dapat berubah selama hidup. Meskipun demikian, tabiat-tabiat "biologis" dapat dikendalikan dengan "menguasai diri". Oleh karena itu, "menguasai diri" atau "zelfbeheersching" disebut dengan tujuan pendidikan dan maksudnya keadaban. "Beschaving is zelfbeheersching" (adab itu, tidak lain dan tidak bukan adalah menguasai diri) (Dewantara, 2011, pp. 23-25).

Teori konvergensi menunjukan bahwa "ajar" dan "dasar" saling berpengaruh. Pendidikan (ajar) memiliki kekuatan atau pengaruh dalam pembentukan watak atau budi pekerti, tetapi pendidikan tidak leluasa dan hanya terbatas oleh garis-garis dasar dari tiap manusia. Oleh karena itu, pendidikan tidak mungkin melenyapkan atau menghilangkan pengaruh kodrat. Sebaliknya, dasar hidupnya manusia sungguhpun kuat tetapi segala "dasar" tersebut tidak mungkin terus bersifat murni atau tidak berubah oleh segala pengaruh dari luar baik yang disengaja (pendidikan) maupun yang tidak disengaja atau pengalaman (Dewantara, 2011, p. 441).

Pada prinsipnya "menguasai diri" berhubungan erat dengan karakter. Menurut Dewantara (Dewantara, 2011, p. 25) budi pekerti, watak, atau karakter dimaknai "bersatunya gerak pikiran, perasaan, dan kehendak atau kemauan yang selalu menimbulkan tenaga. Pandangan ini sejalan dengan Lickona (Lickona, 2009) bahwa pendidikan karakter meliputi tiga hal yaitu, moral knowing (pengetahuan tentang moral), moral feeling (perasaan bermoral), dan moral action (perilaku bermoral).

Watak atau karakter merupakan paduan dari segala tabiat manusia yang bersifat tetap, sehingga menjadi tanda yang khusus untuk membedakan manusia satu dengan yang 
lainnya. Karakter terjadi karena perkembangan dasar yang telah kena pengaruh ajar. "Dasar" sebagaimana telah dijelaskan sebelumnya merupakan kodrat (biologis), sedangkan yang dimaksud dengan "ajar" yaitu segala sifat pendidikan dan pengajaran mulai anak dalam kandungan hingga akil balig yang dapat mewujudkan "intelligible" yakni tabiat yang dipengaruhi oleh angan-angan (Dewantara, 2011, p. 407).

Konsep pendidikan karakter sendiri oleh $\mathrm{Ki}$ Hajar Dewantara disebut dengan pendidikan budi pekerti atau pendidikan adab (Dewantara, 2011, pp. 25-26). Pendidikan karakter atau pendidikan budi pekerti menjadikan manusia sebagai 'manusia merdeka' (berpribadi) yang dapat memerintah atau menguasai diri sendiri. Hal inilah yang disebut sebagai manusia yang beradab. Singkatnya, watak atau budi pekerti yang merupakan "dasar biologis" dapat dipengaruhi oleh pendidikan dan segala pengalaman serta keadaan (Dewantara, 2011, pp. 25-26)).

Pada pelaksanaan pendidikan karakter atau budi pekerti oleh Ki Hajar Dewantara disebut dengan peralatan pendidikan. 'Peralatan' menunjuk pada alat-alat yang pokok, caranya mendidik di antaranya yaitu; 1) memberi contoh (voorbeeld); 2) pembiasaan (pakulinan, gewoontevorming); 3) pengajaran (leering, wulang-wuruk); 4) perintah, paksaan, dan hukuman (regeering en tucht); 5) laku (zelfbeheersching, zelfdiscipline); dan 6) pengalaman lahir dan batin (nglakoni, ngroso, beleving). Alat pendidikan tersebut tidak perlu dilakukan semuanya, misalnya pendidik dari aliran 'vrije opvoeding' (pendidikan bebas) tidak suka menggunakan nomor 4 (perintah, paksaan, dan hukuman). Selain itu, pendidik dapat mementingkan suatu bagian dan pada umumnya memilih cara yang dapat dihubungkan dengan umur peserta didik (Dewantara, 2011).

Pendidikan budi pekerti dilakukan dengan sistem among yaitu, metode pengajaran dan pendidikan berdasarkan asah, asih, dan asuh yang dalam pelaksanaan pengajarannya meliputi kepala, hati, dan panca indera (Wijayanti, 2016, p. 800). Guru atau pendidik pada sistem among berperan; ing sung tuladha, ing madya mangun karsu, tutwuri handayani. Pendidik atau guru yang menjaga sikap dan bicaranya agar menjadi teladan perserta didik, merupakan perwujudan dari konsep ing ngarsa sung tuladha, sedangkan pendidik atau guru yang memotivasi peserta didik adalah wujud dari ing madya mangun karsa. Selain itu, ada kalanya guru atau pendidik bersikap tegas dengan menegur peserta didik yang melakukan kegiatan membahayakan, ini disebut dengan tutwuri handayani (Magta, 2013, p. 229).

Ki Hajar Dewantara, selain mengkaji budi pekerti juga membahas tentang ilmu adab dan etika. Pengertian dari ilmu adab atau etika yaitu ilmu yang mempelajari segala soal kebaikan dan keburukan di dalam hidup manusia, khususnya terkait pikiran dan rasa yang dapat menjadi pertimbangan hingga terjadi suatu perbuatan (Dewantara, 2011, p. 459). Kebaikan dan kejahatan pada akhirnya bergantung pada masing-masing individu, sesuai dengan sifat kejiwaannya dan kejasmaniannya, mulai dari "genotype" sampai "phaenotype" yaitu pandangan hidup, sikap hidup, atau karakter (Dewantara, 2011, p. 461).

Guru memiliki kewajiban mendidik dan mengajar. Bagi Ki Hajar Dewantara kedua hal tersebut memiliki konsep yang berbeda. Mengajar diartikan sebagai kegiatan memberikan pengetahuan, menuntun gerakpikiran, serta melatih kecakapan atau 
kepandaian peserta didik agar kelak menjadi anak yang pintar, pandai, berpengetahuan, dan cerdas. Adapun mendidik berarti menuntun tumbuhnya budi pekerti pada diri peserta didik, agar ia menjadi manusia dengan kepribadian yang beradab dan bersusila (Dewantara, 2011, p. 482). Pengajaran adab dan kesusilaan mengajarkan tentang segala sifat dan bentuk kebaikan dalam hidup manusia, bukan hanya untuk diketahui dan dimengerti, akan tetapi untuk diinsafi, diingini, dikehendaki, dan dilakukan oleh manusia. Pengajaran adab tersebut menekankan pada segala hak dan kewajiban manusia baik sebagai diri pribadi maupun sebagai anggota masyarakat (Dewantara, 2011, p. 483).

Ki Hajar Dewantara menjelaskan pemahamannya terkait dengan pengajaran budi pekerti yang menurutnya merupakan bagian dari pendidikan. Ki Hajar Dewantara menyebutnya sebagai pengajaran pendidikan karena lebih pada hal yang bersifat metodik terkait budi pekerti. Pengajaran budi pekerti dimaknai untuk menyokong perkembangan hidup peserta didik, lahir dan batin, dari sifat kodratnya menuju ke arah peradaban dalam sifatnya yang umum. Contohnya yaitu, meminta peserta didik untuk duduk, tidak berteriak-teriak agar tidak mengganggu peserta didik yang lain, menolong teman, hormat kepada orang yang lebih tua, dll. Hal tersebut merupakan contoh dari pengajaran budi pekerti (Dewantara, 2011, pp. 484-483).

Pengajaran budi pekerti diberikan pada peserta didik disesuaikan dengan tingkat umur. Peserta didik yang mash kecil, pengajaran dilakukan dengan membiasakan agar ia bertingkah laku baik. Pada tahap ini, guru atau pamong memberi contoh, anjuran, atau perintah dan peserta didik melakukan apa yang diinstruksikan. Pada tingkat kedua pengajaran merupakan tingkat 'hakikat' yang bermakna 'kenyataan' atau 'kebenaran'. Pada tahap ini pengajaran diberikan kepada peserta didik yang sudah mampu berpikir berupa pengertian dan pemahaman tentang kebaikan atau keburukan pada umumnya. Peserta didik tidak lagi terikat pada 'pembiasaanpembiasaan' dengan tidak mengetahui akan maksud dan tujuan yang sebenarnya. Bagi para peserta didik yang sudah dewasa, pengajaran dilakukan dengan cara disengaja supaya mereka terlatih melakukan kebaikan meskipun sukar dan berat. Pengajaran pada tingkat dewasa dilakukan dengan memaksa, menekan, atau memerintah untuk menguasai diri pribadi.

\section{Titik Simpul Pemikiran Tagore dan Ki Hajar Dewantara tentang Pendidikan Ideal dalam Membentuk Karakter Peserta Didik}

Kajian terhadap pemikiran Rabindranath Tagore dan Ki Hajar Dewantara pada akhirnya menemukan beberapa poin pokok. Penulis membaginya dalam empat poin pokok yaitu pendidikan, orientasi pendidikan, pengembangan pendidikan, metode atau pendekatan yang digunakan oleh kedua tokoh tersebut. Poin-poin tersebut tersaji dalam tabel berikut ini. 
Tabel Pandangan Tagore dan Ki Hajar Dewantara tentang Pendidikan Ideal

\begin{tabular}{llll}
\hline No. & \multicolumn{1}{c}{ Pandangan } & \multicolumn{1}{c}{$\begin{array}{c}\text { Rabindranath } \\
\text { Tagore }\end{array}$} & \multicolumn{1}{c}{ Ki Hajar Dewantara } \\
\hline 1. & Pendidikan & Kebebasan dan cinta & $\begin{array}{l}\text { Humanis (tanpa paksaan } \\
\text { dan perintah) } \\
\text { 2. }\end{array}$ Orientasi \\
Pendidikan & Pembangunan & $\begin{array}{l}\text { Pikiran, karakter (batin), } \\
\text { dan jasmani }\end{array}$ \\
3. & Pengembangan & $\begin{array}{l}\text { Shantiniketan } \\
\text { Ekperiental learning, }\end{array}$ & Taman Siswa \\
4. & Metode/Pendeka among & \\
& tan & $\begin{array}{l}\text { guru sebagai 'tukang } \\
\text { kebun' }\end{array}$ & \\
\hline
\end{tabular}

Sumber: data diolah penulis, 2016

Rabindranath Tagore dan Ki Hajar Dewantara memiliki banyak persamaan dalam memandang pendidikan ideal. Pendidikan yang dilakukan tanpa paksaan. Tujuan pendidikan menurut Rabindranath Tagore adalah untuk pembangunan, bukan sekadar mencari pekerjaan. Hal yang senada juga dijelaskan oleh Ki Hajar Dewantara bahwa pendidikan berkaitan dengan olah pikiran, budi pekerti, dan jasmani. Rabindranath Tagore dalam mewujudkan pendidikan idealnya mendirikan Shantiniketan dengan menggunakan pendekatan experiential learning yaitu pembelajaran yang menghadirkan pengalaman pribadi sebagai pengalaman belajar. Tagore, menempatkan guru selayaknya 'tukang kebun' dalam merawat peserta didik. Pada sisi yang lain, Ki Hajar Dewantara di Indonesia mendirikan Taman Siswa dengan menempatkan guru sebagai "pamong" atau "among", pembelajaran yang dikembangkan yaitu "asah", "asih”, "asuh”.

Berdasarkan kajian tentang pendidikan dalam perspektif Tagore dan Ki Hajar Dewantara di atas, dapat ditemukan titik simpul pemikiran kedua tokoh tersebut terkait dengan pembentukan karakter peserta didik. Persamaan kedua tokoh tersebut yaitu pada bagian orientasi atau tujuan pendidikan yaitu pembangunan atau pembentukan karakter secara khusus. Hal ini dapat dilihat pada gambar di bawah ini.

Gambar. 1. Titik Simpul Pemikiran Tagore dan Ki Hajar Dewantara tentang Pendidikan dalam Membentuk Karakter Peserta Didik

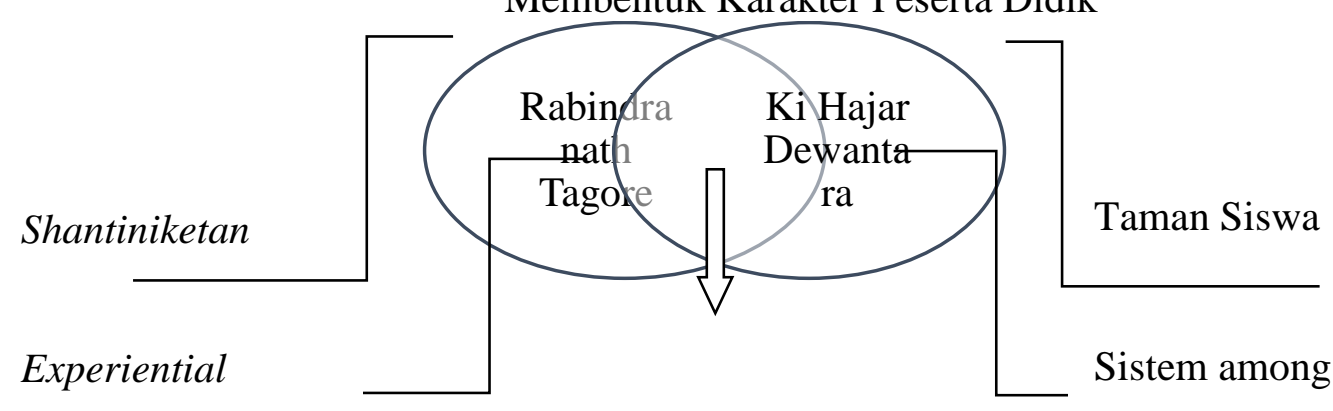

Pendidikan dilakukan tanpa paksaan dan perintah dalam pembentukan karakter peserta didik 
Dengan demikian, kedua tokoh pendidikan tersebut, meskipun berada pada tempat yang berbeda, memiliki konsep dan visi yang hampir sama, yakni keduanya lebih menekankan pada pendidikan budi pekerti atau pendidikan karakter. Tentu keduanya tidak memandang remeh pendidikan yang terkait dengan intelektual peserta didik. Kecerdasan intelektual peserta didik harus dijadikan dasar untuk mengantarkannya pada kecerdasan hati nuraninya.

\section{SIMPULAN}

Pendidikan yang ideal adalah pendidikan yang tidak hanya transfer of knowledge tetapi juga transfer of value. Dengan demikian, pendidikan tidak hanya menghasilkan peserta didik beratribut 'robot cerdas', tetapi juga peserta didik dengan karakter yang baik. Pada tahap ini, guru dan sistem pendidikan memiliki andil yang signifikan.

Model pendidikan Rabindranath Tagore dan Ki Hajar Dewantara layak untuk dikembangkan untuk mewujudkan pendidikan yang ideal, keduanya memiliki persamaan tujuan yaitu untuk pembangunan atau pembentukan karakter peserta didik. Meskipun demikian, gagasan kedua tokoh tersebut bukan tanpa kekurangan. Oleh karena itu, disarankan: 1) pengembangan pendidikan disesuaikan dengan kondisi zaman dan kondisi peserta didik, 2) pemerintah sebagai pengembang sistem pendidikan perlu kiranya mempertimbangkan pemikiran kedua tokoh tersebut untuk modal perbaikan pendidikan ke depan, 3) guru sebagai pelaksana sistem pendidikan harus memposisikan diri bukan hanya sebagai "komando" yang hanya memberi perintah, tetapi juga sebagai 'tukang kebun' atau 'pamong' yang mengawal dan mengawasi proses yang dijalani peserta didik.

\section{DAFTAR PUSTAKA}

Desai, F. P. (2010). Tagore's educational experiments and right to education bill: a comparison. Rupkatha Journal on Interdisciplinary Studies in Humanities, 2(4), 628-640.

Dewantara, K. H. (2011). Bagian pertama: pendidikan (Cetakan Ke). Yogyakarta: Majelis Luhur Persatuan Tamansiswa.

Ghosh, R. (2015). Caught in the cross traffic: Rabindranath Tagore and the trials of child education. Comparative Education Review, 59(3), 399-419.

Guha, M. (2013). Education in a Tagorean Perspective. International Journal of Humanities and Social Science Invention, 2(12), 35-41.

Jha, N. (1999). Rabindranath Tagore. PROSPECTS The Quarterly Journal of Education, 24(3-4), 603-619. http://doi.org/10.1007/BF02195291

Kumalasari, D. (2015). Konsep pemikiran Ki Hadjar Dewantara dalam pendidikan taman siswa (tinjauan humanis-religius). Istoria, 8(1).

Kurniawan, Y., \& Hindarsih, T. P. (2013). Character building; membangun karakter menjadi pemimpin. Yogyakarta: Pro U Media.

Lickona, T. (2009). Educating for character: How our schools can teach respect and responsibility. New York: Bantam Books.

Magta, M. (2013). Konsep pendidikan Ki Hajar Dewantara pada anak usia dini. Jurnal Pendidikan Anak Usia Dini, 7(2), 221-232.

Pridmore, J. (2009). The poet's school and the parrot's cage: the educational spirituality of Rabindranath Tagore. International Journal of Children's Spirituality, 14(4), 355-367.

Putri, I. A. E. (2012). Konsep pendidikan humanistik Ki Hajar Dewantara dalam 
pandangan Islam. Tesis. Tidak Diterbitkan. IAIN Walisongo.

Quayum, M. A. (2016). Education for tomorrow: The vision of Rabindranath Tagore. Asian Studies Review, 40(1), 116.

Samuel, F. A. (2010). Tagore's vision of international education: Relevance and implications for today. In The Educational Forum (Vol. 74, pp. 347356). Taylor \& Francis.

Samuel, F. A. (2011). Educational visions from two continents: What Tagore adds to the deweyan perspective. Educational
Philosophy and Theory, 43(10), 11611174.

Singh, R., \& Rawat, S. S. (2013). Rabindranath tagore's contribution in education. VSRD International Journal of Technical \& Non-Technical Research, 4(8).

Wijayanti, D. (2016). Pendidikan yang memanusiakan manusia (konsep karakter warga negara ideal Ki Hajar Dewantara). In M. Murdiono, Samsuri, B. Mulyono, \& I. Arpannudin (Eds.), Prosiding Konferensi Kewarganegaraan ke-II, UNY (pp. 796-806). Yogyakarta: Jurusan PKnH FIS UNY. 